\title{
Postpartum depression in an Indian community: more prevalent less addressed issue
}

\author{
Aruna Nigam $^{1}$, Anupam Prakash ${ }^{2}$, Neha Maheshwari $^{3}$ \\ ${ }^{1}$ Associate Professor, Hamdard Institute of Medical Sciences and Research, Jamia Hamdard, New Delhi, India \\ ${ }^{2}$ Lady Hardinge Medical College, New Delhi, India \\ ${ }^{3}$ Era's Lucknow Medical College, Lucknow, Uttar Pradesh, India
}

Received: 11 June 2016

Accepted: 02 July 2016

\author{
*Correspondence: \\ Dr. Aruna Nigam, \\ E-mail: prakasharuna@hotmail.com
}

Copyright: () the author(s), publisher and licensee Medip Academy. This is an open-access article distributed under the terms of the Creative Commons Attribution Non-Commercial License, which permits unrestricted non-commercial use, distribution, and reproduction in any medium, provided the original work is properly cited.

\begin{abstract}
Background: Postpartum depression is major health concern which not only has effect on maternal mortality and morbidity but also have effect on the cognitive and behavioral development of the child. Aims of the study was to study the prevalence of postpartum depression and its correlates.

Methods: 100 women between 2 to 6 weeks of postpartum period were subjected to a pre-tested pre-structured standard questionnaire. Diagnosis of depression was made using the Edinburgh Postnatal Depression Scale. Possible depression is suggested by a score of 10 or greater; while values equal to 13 or more are invariably associated with depression.

Results: The average age of the study group was $28.67 \pm 5.22$ years and average duration of the post-partum period was $28.12 \pm 10.94$ days. There was only one single parent in the study group; $77 \%$ were Hindus, $23 \%$ Muslims; $72 \%$ were housewives, while $22 \%$ were laborers. All subjects belonged to the low or middle socioeconomic groups. Onethird of the subjects were illiterate. $93 \%$ had scores $>13$ by use of the Edinburgh Postnatal Depression Scale. $89 \%$ of the subjects had five or more contributory factors out of 21 contributory factors studied. The most common contributory factors were- child care stress, life stress, low self-esteem, low social support, infant temperament problems, low socioeconomic status, prenatal depression and prenatal anxiety.

Conclusions: There is high prevalence of postpartum depression outskirts of Lucknow. Thus it appears pertinent to screen all women for postpartum depression after child-birth in this area so as to improve maternal and child health.
\end{abstract}

Keywords: Anxiety, Depression, Prevalence, Postpartum period

\section{INTRODUCTION}

During the postpartum period, up to $85 \%$ of women experience some type of mood disturbance. In most women, symptoms are transient and mild, and are referred to as postpartum blues; however, it is the postpartum depression experienced by women, which is more disabling and is a persistent form of mood disturbance. $^{1,2}$ Postpartum depression may occur up to one year after childbirth, and its spectrum may range from mild depression to severe depression with suicidal tendencies.
Post-partum depression is the most common and serious medical complication of child-bearing. ${ }^{3}$ Despite this fact, too often, postpartum depression is dismissed as a normal or natural consequence of childbirth. It is very important to recognize postpartum depression because mothers with postpartum depression unconsciously exhibit fewer positive emotions and more negative emotions towards their children, are less responsive and less sensitive to infant cues, are less emotionally available, have a less successful maternal role attainment, and have infants that are less securely attached; and in extreme cases, some women may have thoughts of harming their children and make mother insensitive with child care. ${ }^{4}$ 
More importantly, one must note that in most cases postpartum depression is preventable and is largely treatable. In fact, early identification can lead to early treatment. A major part of prevention is being informed about the risk factors and the medical community can play a key role in identifying and treating postpartum depression. Women should be screened by their physician to determine their risk for acquiring postpartum depression. However, published literature from India is scant on this aspect. This study is planned to determine the proportion of females (delivering in-hospital) suffering from postpartum depression and identify the correlates of postpartum depression in and around Lucknow; so that strategies may be evolved to reduce the morbidity costs attributable to the mother and child in future. The aims of this study were to study the prevalence of postpartum depression in population residing in and around Lucknow and to study the correlates of postpartum depression.

\section{METHODS}

A cross-sectional study was performed over a period of two months among women attending out-patient department (post-natal clinic and immunization clinic) of Gynaecology and Obstetrics of Era's Lucknow Medical College and hospital, Lucknow, Uttar Pradesh. It is situated in the periphery of lucknow and mainly caters the suburban and the rural population. A total of 100 women, who were in their postpartum state were evaluated for the prevalence of postpartum depression. All women who were in the postpartum period (up to 6 weeks after childbirth), excluding those who had childbirth within the last 2 weeks, were subjected to a pre-tested, pre-structured, standardised questionnaire, after obtaining an informed written consent. Women who have had childbirth in the previous two weeks were excluded from the study since they could be suffering from postpartum blues. The study proposal was approved by the Institutional Ethics Committee for conduct in the institute.

Diagnosis of depression was made using the Edinburgh Postnatal Depression Scale (EDPS). ${ }^{5}$ The EDPS is a ten question scale and each scale has four weighted answers from 0 to 3 ; maximum score being 30 and minimum being zero (0). Possible depression is suggested by a score of 10 or greater. The scale was administered by the investigator in the language known to the patient for ease of understanding, which was Hindi.

A detailed clinical history and a complete general physical examination were performed for each subject. Subjects who provided their consent to get investigated were additionally investigated for haemoglobin, total and differential leucocyte counts, random plasma glucose, blood urea, serum creatinine, serum glutamate pyruvate transaminase, serum alkaline phosphatase, serum TSH (thyroid stimulating hormone) levels and urine-routine and microscopic examination.
Various determinants that were evaluated for their presence in our study group, to ascertain the correlates of postpartum depression are enlisted below;

1. Prenatal depression i.e. during pregnancy

2. Low self-esteem

3. Child care stress

4. Prenatal anxiety

5. Life stress

6. Low social support

7. Poor marital relationship

8. History of previous depression

9. Infant temperament problems/colic

10. Maternity blues

11. Single parent

12. Low socioeconomic status

13. Unplanned/unwanted pregnancy

14. History of genetic mental illness

15. Substance abuse

16. Former childbirth issues

Other features that were also enquired in to, included the following;

1. Religion

2. Age of mother

3. Number of pregnancies

4. Number of abortions

5. History of treatment for Infertility

6. Normal vaginal delivery or caesarean section in the last delivery

7. Failure to breast-feed/Lactational failure/Insufficient milk production

8. Present or past intrauterine demise

9. Presence of co-morbid illnesses

The collected data was tabulated on a windows based personal computer using an excel worksheet. Prevalence of postpartum depression was calculated. The frequency of correlates of postpartum depression and other determinants were studied in the group with postpartum depression.

\section{RESULTS}

The average age of the study group was $28.67 \pm 5.22$ years with average duration of the post-partum period being $28.12 \pm 10.94$ days. All subjects were married, but one 
subject was a widow. Hindus comprised $77 \%$, while $23 \%$ were Muslims; $72 \%$ were housewives, $22 \%$ were labourers, $4 \%$ were workers in shops while $2 \%$ were teachers. All subjects belonged to the low, low middle and middle socioeconomic groups. The per capita income was Rs. $856.33 \pm 571.34$ per month. One-third of the subjects $(33 \%)$ were illiterate, $2 \%$ had received primary education, $7 \%$ had passed their high school (Class X) and $21 \%$ had passed intermediate (Class XII). One-third (33\%) were graduates while $4 \%$ had postgraduate qualifications.

Table 1: Frequency of answers obtained for each arm of the ten questions $(n=100)$.

\begin{tabular}{|lllll|}
\hline Question no. & a & b & c & d \\
\hline 1. & 5 & 75 & 17 & 3 \\
\hline 2. & 14 & 54 & 29 & 3 \\
\hline 3. & 12 & 58 & 24 & 6 \\
\hline 4. & 20 & 48 & 28 & 4 \\
\hline 5. & 31 & 44 & 20 & 5 \\
\hline 6. & 22 & 55 & 17 & 6 \\
\hline 7. & 36 & 34 & 25 & 5 \\
\hline 8. & 35 & 38 & 25 & 2 \\
\hline 9. & 29 & 44 & 21 & 6 \\
\hline 10. & 18 & 47 & 31 & 4 \\
\hline
\end{tabular}

Table 2: Prevalence of contributing/predisposing factors $(n=100)$.

\begin{tabular}{|ll|}
\hline Contributing conditions/factors & N \\
\hline Prenatal Depression & 51 \\
\hline Prenatal anxiety & 49 \\
\hline Poor marital relationship & 37 \\
\hline Infant temperament problems/colic & 78 \\
\hline Unplanned/unwanted pregnancy & Nil \\
\hline Last delivery caesarean & 26 \\
\hline History of treatment for infertility & 2 \\
\hline Low self-esteem & 82 \\
\hline Life stress & 90 \\
\hline History of previous depression & 25 \\
\hline Single parent & 1 \\
\hline History of genetic mental illness & 6 \\
\hline Child care stress & 94 \\
\hline Low social support & 81 \\
\hline Maternity blues & 18 \\
\hline Low socioeconomic status & 77 \\
\hline Substance abuse & 4 \\
\hline Present or past intrauterine demise & Nil \\
\hline Breast-feeding problems in present pregnancy & 2 \\
\hline Presence of co-morbid illnesses & 12 \\
\hline Number of abortions & 2 \\
\hline
\end{tabular}

Among the study group, $46 \%$ had more than two children and $24 \%$ had one issue while $30 \%$ had two issues.
The frequency of scores for each arm of the ten questions asked from each subject in the study is indicated in table 1 of the study group, $18 \%$ had affirmed that the thought of harming themselves had occurred to them quite often, and another $47 \%$ said this thought had crossed their minds sometimes.

The total score obtained by use of the EDPS was less than 10 in only four cases (4\%). However, 3\% of the cases studied had a score between 10 to 13 suggesting possible depression, while $93 \%$ had scores of more than thirteen indicating that postpartum depression was almost definite in these cases.

Table 2 describes the prevalence of contributory factor for postpartum depression. Of the 21 contributory factors asked from each subject, $89 \%$ of the subjects had five or more factors present simultaneously, while $11 \%$ of the subjects had four or less contributory factors present. However, 4\% subjects had more than 10 contributory factors present. The most common contributory factors encountered were- child care stress (94\%), life stress (90\%), low self-esteem (82\%), low social support (81\%), infant temperament problems $(78 \%)$, low socioeconomic status $(77 \%)$, prenatal depression $(51 \%)$ and prenatal anxiety (49\%).

Serum TSH levels which could be performed in 35 subjects were within normal limits and all subjects had a haemoglobin level above $9 \mathrm{~g} / \mathrm{dL}$.

Of the four subjects who were not depressed, were well educated, 28 years Hindu housewives, having per capita income of Rs. 1000/- per month and one prior pregnancy.

\section{DISCUSSION}

The postpartum state in a female is a very special state, not only physically and socially but also emotionally. It requires extraordinary care which in our country at times becomes difficult. The present socioeconomic milieu of an individual and the past along with to some extent the genetic make-up determine the prevalence of depression in this period (postpartum depression or postnatal depression). This study has outlined the fact that postpartum depression is quite common in this part of the country. At this point, it will be pertinent to point out that the study was conducted at Era's Lucknow Medical College which is situated on the outskirts of the city (Lucknow) and caters to a mix of population largely from the rural and semi-urban areas including small townships situated in the surrounding districts of Unnao, Sitapur and Hardoi. It is also worthwhile to mention here that Uttar Pradesh is the most populous state of India and is one of the BIMAROU states of India, an acronym for Bihar, Madhya Pradesh, Assam, Rajasthan, Orissa, Uttar Pradesh which are the lowest ranked states of India on the development and the social indicator scales. During the postpartum period, up to $85 \%$ of women experience some form of mood disturbance. Fortunately for most women, 
symptoms are transient and relatively mild (labelled as postpartum blues), but 5 to $25 \%$ of women experience a more disabling and persistent form of mood disturbance in form of postpartum depression. ${ }^{1,2,6}$ The methodological differences in ascertaining the diagnosis, however, make the actual prevalence rates unclear. Interestingly, in this study, 93\% subjects were suffering from postpartum depression. Such a high prevalence could be attributed to the poor socioeconomic profile of the state and a mix of rural and semi-urban population. Although, similar high prevalence has not been reported earlier, but the postpartum depression rate for pregnancies subsequent to the initial post-partum episode has been reported to be $75 \%$. $^{3}$ Moreover, there has not been any study reported on postpartum depression from this part of the country. Villegas et al have found the post-partum depression prevalence of $31 \%$ (CI-21.35-43.5\%) among rural women in developing countries. ${ }^{7}$ Another metanalysis quotes the prevalence of postpartum depression in Asian countries ranged from $3.5 \%$ (in Malaysia) to $63.3 \%$ (in Pakistan). ${ }^{8}$

This study might have slightly over-estimated the prevalence of postpartum depression, because it was a cross-sectional (one-time) study although the EDPS does ask about the persistence of symptoms for 7 days, but it could have been over-reported by subjects. A second follow-up after a week or two would have authenticated it further, however, two time interaction was not feasible because of the short duration of this study. Moreover, drop-out rates would have been higher in a follow-up study thus, shrinking the sample size.

Various important correlates that were found in this study were child care stress (94\%), life stress (90\%), low selfesteem (82\%), low social support (81\%), Infant temperament problems $(78 \%)$, low socioeconomic status $(77 \%)$, prenatal depression $(51 \%)$, and prenatal anxiety (49\%). The results in our study are corroborated with the contributory factors as were reported by Beck in a metaanalysis and the commonest 6 factors as reported by Beck are important factors found in our study as well. ${ }^{9,10}$ Only infant temperamental problems and low socio-economic status ranked higher up in our study and this may partly be because of different socio-cultural values as the family system is much stronger in our country and moreover, the peculiar socio-demographic profile including largely semi-urban and rural populace could have resulted in higher prevalence of the "low socioeconomic status" as a contributory factor. Low socioeconomic status has been found to be important contributory factor in the study from Kolkata also. ${ }^{11}$ Prior history of depressive disorders, lack of social support, and stressful life events all have been reported to increase the risk of post-partum depression and these factors were also reported to be important contributory factors in this study. ${ }^{4}$ The causal role of lack of social support and other childcare stressors in postpartum depression is also strongly suggested by several other studies. $^{12-15}$
This study is a novel pilot study, especially when similar studies are lacking from this part of the country. This study is a small step in this direction and we earnestly believe that post-partum depression is acting as an important co-morbidity for both the lactating mothers and their infants.

\section{CONCLUSION}

The prevalence of postpartum depression is $93 \%$ as found in this hospital-based study comprising of subjects from the semi-urban and rural areas around Lucknow. The high prevalence rates of postpartum depression as have been highlighted by this study are an eye-opener and may be important contributory factors to high maternal and infant mortality seen in this part of the country. Important contributory factors found in the study were- child care stress, life stress, low self-esteem, low social support, infant temperament problems, low socioeconomic status, prenatal depression and prenatal anxiety. Multiple contributory factors (five or more) were present simultaneously in $89 \%$ of the subjects. We recommend screening of all mothers during the post-partum period on the basis of this study and institution of prompt treatment of the same. It would be prudent to screen mothers of infants for postpartum depression at each contact with the health facility, whether immunization clinics or national programmes or at the anganwadis.

Funding: No funding sources Conflict of interest: None declared

Ethical approval: The study was approved by the Institutional Ethics Committee

\section{REFERENCES}

1. Kemp B, Bongartz K, Rath W. Psychic disturbances in the postpartum period: an increasing problem? $\mathrm{Z}$ Geburtshilfe Neonatol. 2003;207:159-65.

2. Nonacs R, Cohen LS. Postpartum mood disorders: diagnosis and treatment guidelines. J Clin Psychiatry. 1998;59(suppl 2):34-40.

3. Garvey MJ, Tuason VB, Lumry AE, Hoffmann NG. Occurrence of depression in the postpartum state. $\mathbf{J}$ Affecti Disord. 1983;5:97-101.

4. Beck CT. The effects of postpartum depression on maternal-infant interaction: a meta-analysis. Nursing Research. 1995;44:298-304.

5. Cox JL, Holden JM, Sagovsky R. Detection of postnatal depression: Development of the 10-item Edinburgh Postnatal Depression Scale. British Journal of Psychiatry. 1987; 150:782-6.

6. Pedersen CA. Postpartum mood and anxiety disorders: a guide for the nonpsychiatric clinician with an aside on thyroid associations with postpartum mood. Thyroid. 1999;9:691-7.

7. Villegas L, McKay K, Dennis CL, Ross LE. Postpartum depression among rural women from developed and developing countries: a systematic review. J Rural Health. 2011;27:278-88. 
8. Klainin P, Arthur DG. Postaprtum depression in Asian cultures: a literature review. Int J Nrs Stud. 2009;46:1355-73.

9. Beck CT. A meta-analysis of the relationship between postpartum depression and infant temperament. Nursing Research. 1996;45:225-30a.

10. Beck CT. A meta-analysis of predictions of postpartum depression. Nursing Research. 1996;45:297-303b.

11. Ghosh A, Goswami S. Evaluation of postpartum depression in a tertiary hospital. J Obstet Gynaecol India. 2011;61:528-30.

12. Navarrete LE, Lara-Cantu MA, Navarro C, Gomez ME, Morales F. Psychosocial factors predicting postnatal anxiety symptoms and their relation to symptoms of postpartum depression. Rev Invest Clin. 2012;64:625-33.
13. Razuel C, Kaiser B, sellenet C, Epiney M. Relation between perceived stress, social support, and coping strategies and maternal well-being: a review of the literature. Women health. 2013;53(1):74-99.

14. Gotlib IH, Whiffen VE, Wallace PM, Mount JH. Prospective investigation of postpartum depression: factors involved in onset and recovery. Journal of Abnormal Psychology. 1991;100:122-32.

15. Beck CT. Predictors of Postpartum Depression: An Update. Nursing Research. 2001;50:275-85.

Cite this article as: Nigam A, Prakash A,

Maheshwari N. Postpartum depression in an Indian community: more prevalent less addressed issue. Int J Reprod Contracept Obstet Gynecol 2016;5:2691-5. 